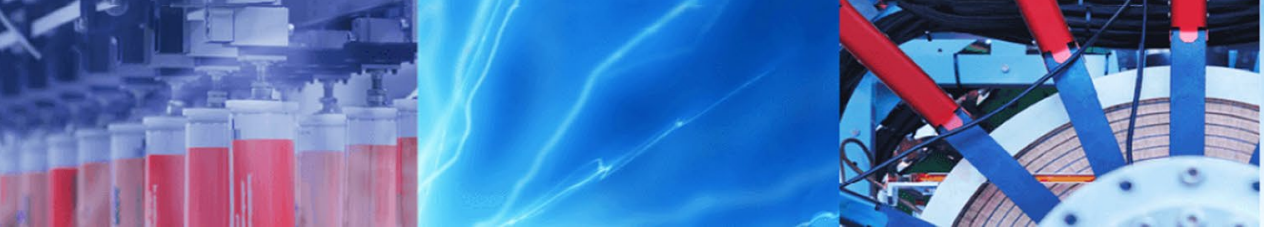

Research Article

\title{
High-pressure compacted recycled polymeric composite waste materials for marine applications
}

\author{
Edward Clark ${ }^{1} \cdot$ Monika Bleszynski $^{1} \cdot$ Matt Gordon $^{1}$ \\ Received: 13 September 2021 / Accepted: 30 November 2021 \\ Published online: 04 January 2022 \\ (c) The Author(s) 2021 OPEN
}

\begin{abstract}
Abstract Options for recycling fiber composite polymer (FCP) materials are scarce, as these materials cannot be normally recycled and are toxic when improperly disposed. Additionally, reducing water usage is an increasing concern, as the concrete industry currently uses $10 \%$ of the world's industrial water. Therefore, building upon our previous work, this research explores the use of polymer hybrid carbon and glass composite waste products as reinforcements in highpressure compacted cement. Our material used nearly $70 \%$ less water during manufacturing and exhibited improved durability and salt corrosion resistance. Compression strength tests were performed on high-pressure compacted materials containing $6.0 \mathrm{wt} \%$ recycled admixtures before and after saltwater aging, and the results showed that the material retained $90 \%$ of its original compression strength after aging, as it contained fewer pores and cavities. Our experimental work was supplemented by molecular dynamics. Simulations, which indicated that the synergetic effects of compaction and FCP admixture addition slowed the diffusion of corrosive salt ions by an average of $84 \%$. Thus, our high-pressure compacted cement material may be suitable for extended use in marine environments, while also reducing the amount of commercial fiber composite polymer waste material that is sent to the landfill.
\end{abstract}

\section{Article Highlights}

- Fiber composite waste was successfully recycled into denser, high-pressure compacted ordinary Portland cement materials.
- High-pressure compacted cement samples containing $6 \%$ recycled admixtures retained $90 \%$ of their compression strength after salt aging.

- The high-pressure compaction method utilized $70 \%$ less water during specimen fabrication.

Keywords Recycled polymer waste $\cdot$ Cement $\cdot$ High pressure $\cdot$ Salt aging $\cdot$ Molecular dynamics

\section{Introduction}

Fiber composite polymers (FCPs) have many advantages for material applications, such as high durability, excellent strength to weight ratio, and extended service life, and are therefore frequently used by industry manufacturers. Worldwide mass production of polymer fiber composite materials includes adhesives, plastic thermosets, and resins, however, most of these materials are unfortunately non-decomposable. Additionally, large amounts of composite waste are generated by the utility and engineering industries every year, most of which is sent to the landfill, and studies have shown that FCP material waste products will surpass 194 kilotons globally [1-5]. Unfortunately, with

Monika Bleszynski, mbleszyn@du.edu|' University of Denver, Denver, CO 80208, USA. 
increasing production of FCP products containing carbon and glass fibers, the quantity of post-end of life materials being sent to landfills will only increase [1-5].

One source of FCP waste comes from power and electrical distribution utilities, which use composite conductor rods consisting of carbon and glass composite high-voltage conductor cores (HVCC) for their transmission lines. These HVCC rods contain hybridized carbon, glass fibers, and epoxy materials, which cannot be readily recycled. As a result, postproduction waste, excessively damaged rods, and expired end-of-life HVCC materials are often discarded.

A major issue with these materials is the thermoset resin, which cannot be easily separated from the carbon and glass fibers. Recycling hybridized FCP is problematic because the methods used to separate the carbon or glass fibers and reliquify the thermoplastic resin are limited to certain fibers, heat conditions, and mechanical constraints. Thus, large quantities of carbon and glass composites are not recycled because these procedures can mechanically degrade fiber quality. Fortunately, there are other ways to recycle FCP waste that have proven advantages such as physically or chemically recycling composite waste into existing materials such as cement and concrete structures, and these methods are more environmentally conscious than landfill disposal [3-5].

Presently, highly versatile corrosion-resistant cement matrix structures, such as pillar supports, wind energy structures, and coastal shore walls (barriers) are desired for marine water-based environments. A large majority of these industrial components frequently consist of cement-based concrete materials, which can withstand continuous impacts from ocean waves [6-10]. These structures are often based upon Portland cement, due to the material's chemical tolerance and high compressional high strength [6-9]. Unfortunately, even though Portland cement is tough and sturdy, it is not impenetrable to corrosive seawater environments, and must endure the destructive impacts of ocean water while being continuously exposed to salt-based corrosive compounds $[11,12]$. Large concrete structures contain many open pores and internal gaps (spaces), anywhere between 10 and 20\%, and these pores provide access points for water and saltwater, which can destroy the material over time [13-15]. As a result, a decline in mechanical strength often occurs within a few years due to surface degradation (pitting), development of large cracks, and internal expansions caused by water ingress $[7-9,16,17]$, all of which physically compromise the overall structure [16-18].

The deterioration of various concrete structures can also be attributed to the fabrication and design quality of the component, which for cement-based materials is based upon the magnitude of surface and internal gaps or spaces $[6-9,13]$. In some cases, severe deterioration due to seawater ingress may occur within a few years, resulting in surface defects and large cracks. These issues are often combined with internal swelling caused by sulfate attack, chloride ingress, and freeze thaw expansion, which can lead to structural collapse or failure if not mitigated or prevented [6-14]. This phenomenon is due calcium hydroxide and aluminate hydrates reacting with sulfate ions, which can cause internal expansion due to the formation of calcium aluminate trisulfate, also known as ettringite. Deterioration from chemical sulfate expansion, ingress of chloride, and water expansion as a result of freezing can cause calcium leaching, which can further deteriorate and weaken the hardened cement paste [19]. Therefore, reducing the number of pores and voids in cement-based structures is crucial for structure longevity.

Previous studies have found that carbon and glass fibers in cement-based concrete can increase the qualities of the material, such as mechanical strength, life-span, and overall toughness [5, 20-23]. Thus, instead of being sent as waste to landfills, admixture FCP fillers may be used in high density cementitious materials, reducing the amount of water that needs to be used for mixing while also enhancing its pitch [5, 20-24]. Our previous work assessed the feasibility of introducing carbon fiber waste into standard ordinary Portland cement materials, and our results showed that certain FCP products improved the cement's resistance to salt aging, specifically due to the presence of the carbon and glass fiber material [5]. Therefore, to address the above-mentioned issues, we incorporated a high-pressure compaction machine to increase material density. Then, we assessed if high-pressure compacted materials containing reclaimed recycled HVCC materials can be used in highly corrosive environments, such as offshore and marine applications. Subsequently, our system utilized nearly $70 \%$ less water during fabrication, but created a denser material with fewer voids and cavities, which is critical for the concrete industry which currently uses $10 \%$ of the world's industrial fresh water [25].

\section{Materials and methods}

Cementitious materials can be improved through the addition of additives known as chemical admixtures, and these materials are specifically tailored to improve the mechanical performance of cement mixtures for certain construction applications. In this study, we combined Portland cement with various HVCC FCP admixtures, denoted in this study as recyclate. We also used a high-pressure compaction system to decrease the porosity of the material, while also reducing the amount of water required during fabrication. 


\subsection{Ordinary portland cement (matrix)}

Portland cement is composed of several main constituents, which are listed in Table 1. Cement is cured in several stages, regardless of whether it is commercially created in a factory and then transported to a construction site or mixed on-site and poured into molds or castings. While the hydration curing process results in a hardened paste cement within $24 \mathrm{~h}$, the Portland cement will continue to cure long after its initial construction, even with non-hydrated compounds [16, 18, 25-27]. Not all types of cement are manufactured the same, and full hydration and maximum compression strengths may increase with age. Depending on setting (curing) environmental conditions, most nonblended cementitious based products in openair will reach maximum compression strength by 28 days, while for blended mixtures the maximum compression strength is achieved in 56 days. Therefore, it is standard practice to test strengths between 7 and 56 days after curing $[16,18,25-27]$.

Several cement studies have noted that while water is a crucial ingredient in the initial mixing of cement, too much can hinder maximum compression strength, while too little can reduce workability and result in a weaker product $[16,18,25,27,28]$. Although water and ordinary Portland

Table 1 Composition of construction grade ordinary Portland cement type I/II by (wt\%) [18]

\begin{tabular}{lc}
\hline Constituent & $\begin{array}{l}\text { Weight } \\
\text { percentage } \\
\text { (approx.) }\end{array}$ \\
\hline $\mathrm{CaO}$ & 64.64 \\
$\mathrm{SiO}_{2}$ & 21.28 \\
$\mathrm{Al}_{2} \mathrm{O} 3$ & 5.60 \\
$\mathrm{Fe}_{2} \mathrm{O}_{3}$ & 3.36 \\
$\mathrm{MgO}$ & 2.06 \\
$\mathrm{SO}_{3}$ & 2.14 \\
$\mathrm{Trace}$ amounts (other) & $<2.0$ \\
\hline
\end{tabular}

Common compounds noted by construction cement manufacturers cement are the primary ingredients, rocks (aggregate) are added to increase volume and lower cost, and when sand is added in addition to aggregate, it results in hydraulic concrete $[16,18,25,27,28]$. For basic construction purposes, standard high-strength concrete usually is $\sim 60$ to $80 \%$ coarse or fine aggregate $[5,18,25,27,28]$ Often, specialized additives are added to cement mixtures, such as silica-fume, fly-ash, small pebble (gravel), and larger diameter course or smooth rock aggregate.

Because the presence of open pores and internal gaps (spaces) can assist or accelerate moisture ingress and destroy the material over time, mitigating internal porosity and increasing the density of concrete products may be crucial for extending their service life in marine environments. With this in mind, we incorporated a high-pressure compaction system to reduce the porosity of the final ordinary Portland cement/HVCC powder composite material. Because it is vital to have a semi-liquid paste that can be easily poured and formed into molds, using the least amount of water possible, a compaction method created a final product with reduced pores or voids $[16-18,25$, 27-29]. In this design, we followed the ASTM C150 standard and used commercial-grade Portland cement type I/ II as the matrix with very low amounts of aluminates for moderate sulfate resistance, and recycled FCP materials were used as the admixtures [30].

\subsection{Background on the vibration dynamic compaction system}

To create a dense cement product, a custom-designed high-pressure system was used (Fig. 1a). This vibratory dynamic compaction technology was adapted from the mining and tilling industry, and used twin 4000-Watt, 3-phase $50 \mathrm{~Hz}$ oscillating vibrators. This technology has been used to crush and compress geo-earth materials, as well as manufacture construction blocks and panels from coal fly ash, mining quarry tailing and rock, recycled concrete, granular industrial waste materials, and waste soils to form blocks, panels, and other geometries (Fig. 1b) [31-35].
Fig. 1 a, b. Dynamic highpressure compaction system (a), high-pressure compacted Portland cement particle fiber mixed block (b)
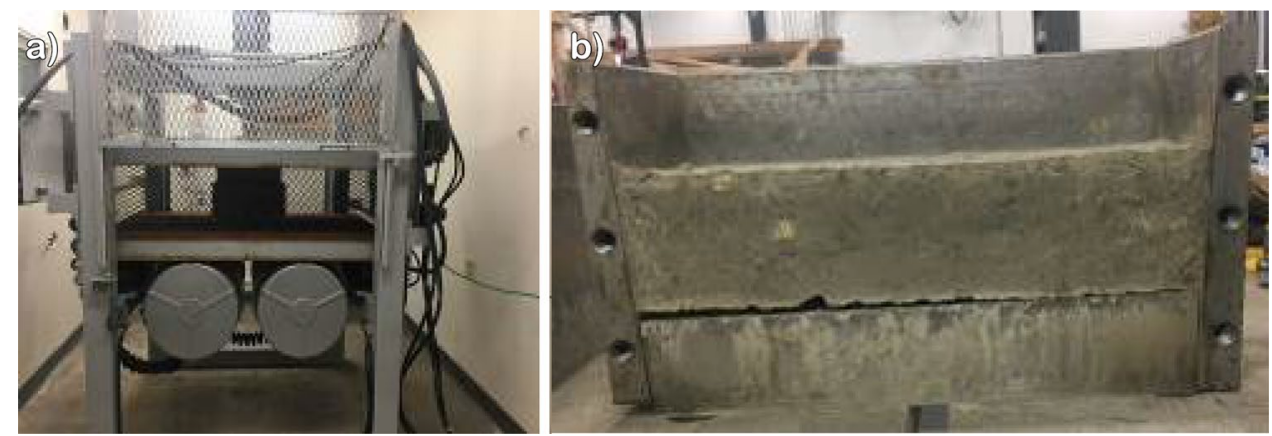
This specific compaction system could compact Portland cement into tough durable blocks, making it ideal for creating large cementitious products [31-33]. In previous research conducted for the Department of Energy (DOE), this machine was successfully used to compact and stabilize contaminated soil, which allowed for safer storage, transportation, and disposal [31, 33].

The principle of dynamic vibration powder pressing relies on using repetitive pulverizing action. Because of the way the cement materials compress and cure, a lower kinetic energy pressure on the powder material will result in less compacted, higher void, and lower density material, while high-velocity impact compaction with an estimated peak impact force of $\sim 2000 \mathrm{kN}$ from the dynamic compaction system will result in a higher density surface to volume ratio. Therefore, when manufacturing a high-density material from a loosely packed powder, substantial density variations within the material's structure could be attributed to the high-velocity punching action of the upper anvil. To reduce this inhomogeneity problem within a compacted powder, oscillating vibratory forces from the lower steel table and mounted compaction mold were used to maximize the uniformity of material compression and the cementitious admixtures by $\sim 40 \%$ by volume of the steel mold (Fig. 2b).

The main challenges of high-density compaction recycling of HVCC material are the mechanical material preparation and finding the optimal density to achieve high mechanical strengths and durability. The high-pressure compaction process ameliorated this by requiring less water than the traditional method for creating solid cement hardened products. While traditional concrete fabrication methods use around 33\% water, only $10 \%$ water was used in this high-pressure compaction system (Table 2, Fig. 3). Thus, with the addition of microparticles from the Portland cement binder, and composite recyclate particles averaging $52.85 \mu \mathrm{m}$ in size, water usage

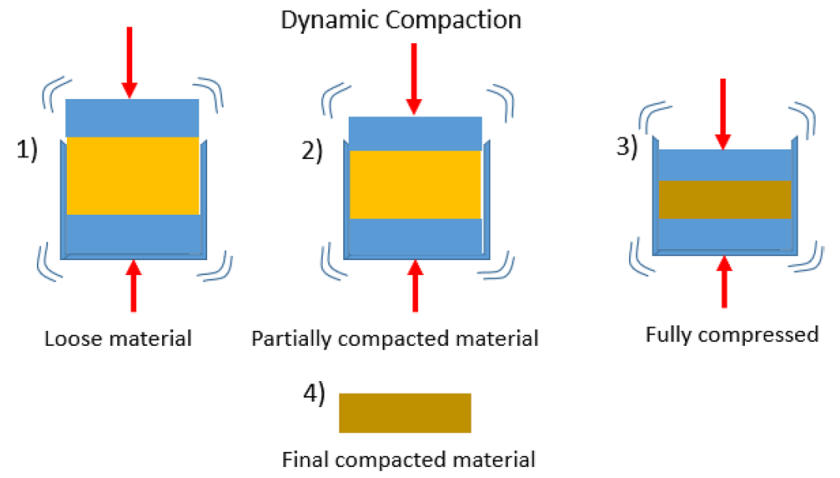

Fig. 2 Diagram of the dynamic high-pressure compaction system, showing a reduction of the cement by $40 \%$ by volume in the fully pressed material
Table 2 Mixture proportions of cement powder (wt\%)

\begin{tabular}{llll}
\hline Compaction & Water ratio & Cement & Recyclate \\
\hline HP & 10 & 100 & 6.0 \\
LP & 33.33 & 100 & 6.0 \\
\hline
\end{tabular}

was reduced by $70 \%$ using the high-pressure compaction method, compared to the low-pressure, hand compaction method. Thus, if successful, this approach would help reduce overall water consumption in the cement industry [5].

\subsubsection{Polymer composite fibers (admixture)}

The HVCC polymer rod (also known as the conductor core) polymer matrix material used in this design was designed and manufactured by Composite Technology Corporation (CTC) Global. The composite matrix material was made of unidirectional hybrid carbon covered in a glass fiber shell. The matrix consisted of an epoxy resin, which is a highheat resistant thermoplastic resistant to extreme temperature environments [5]. For the purposes of this study, the HVCC rod was cut and mechanically ground down to create a finer admixture pitch to include in the cement as the recyclate.

In this study, two recyclate HVCC admixtures were used: finely ground HVCC composite powder with an average particle size of $\sim 52.85 \mu \mathrm{m}$, and crushed HVCC 'chips' which were $\sim 8-10 \mathrm{~mm}$ in length and $\sim 2-5 \mathrm{~mm}$ in width. The two admixtures are shown in Fig. $4 a$, which were made using the methods described in our previous work [5]. For comparison, virgin polyacrylonitrile (PAN) carbon fibers and glass fibers were also included in this study, to compare with the HVCC "recyclate". The PAN fibers were produced by Toray Industries, Inc., while the chopped E-glass fibers were attained from a commercial distributor. The FCP admixtures were also produced from newly manufactured $\mathrm{HV}$ conductor core rods.

In this work, $6.0 \mathrm{wt} \%$ of the "recyclate" admixture material was incorporated into the cement, and workability was evaluated by according to the ASTM standards $[5,30]$ The recyclate admixture was combined with $10 \%$ water, after which the entire mixture was placed into a steel compaction mold (Fig. 4b), and then placed on the dynamic compaction base steel plate. The upper steel top plate with an anvil was then lowered to gently press the loose, moist cement powder mixture together (Fig. 5a). Dynamic compaction was then performed for 5-7 s, compressing the mixture into a dense solid.

A total of four different rectangular blocks were created using the dynamic compaction system, as shown in Fig. 6a: (1) $6.0 \mathrm{wt} \%$ virgin carbon/glass fiber + Portland cement, 
Fig. 3 Comparison of total mass percentages of materials for mixing designs high-pressure vs. low-pressure compaction
High-Pressure Compaction

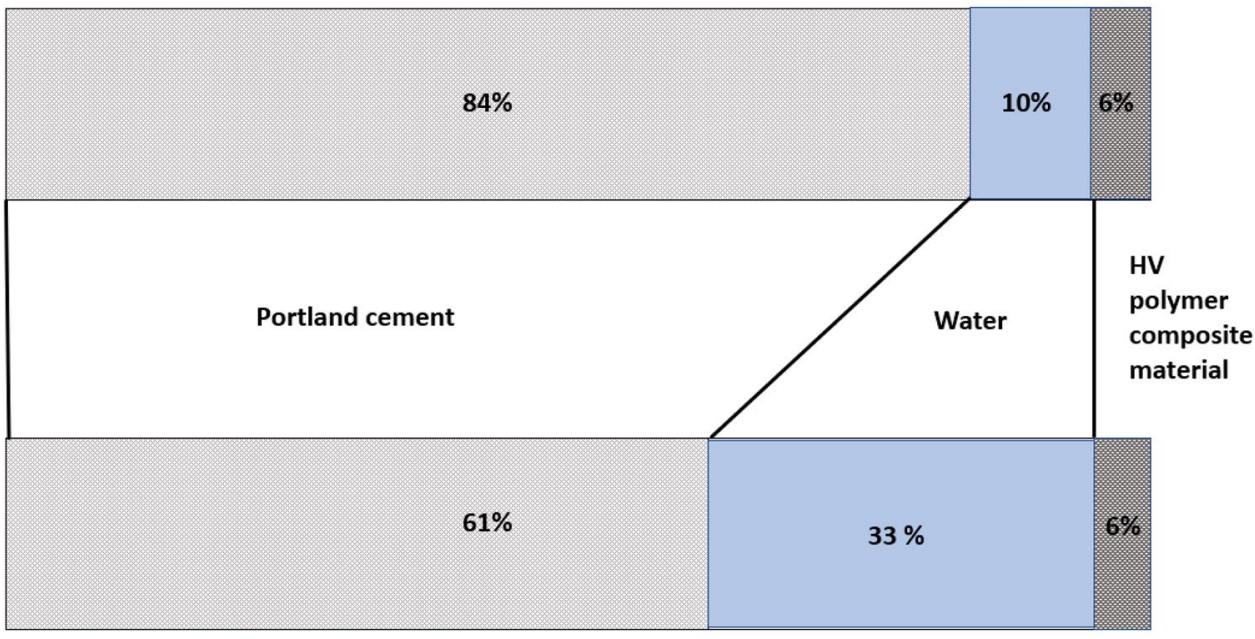

Low-Pressure Compaction
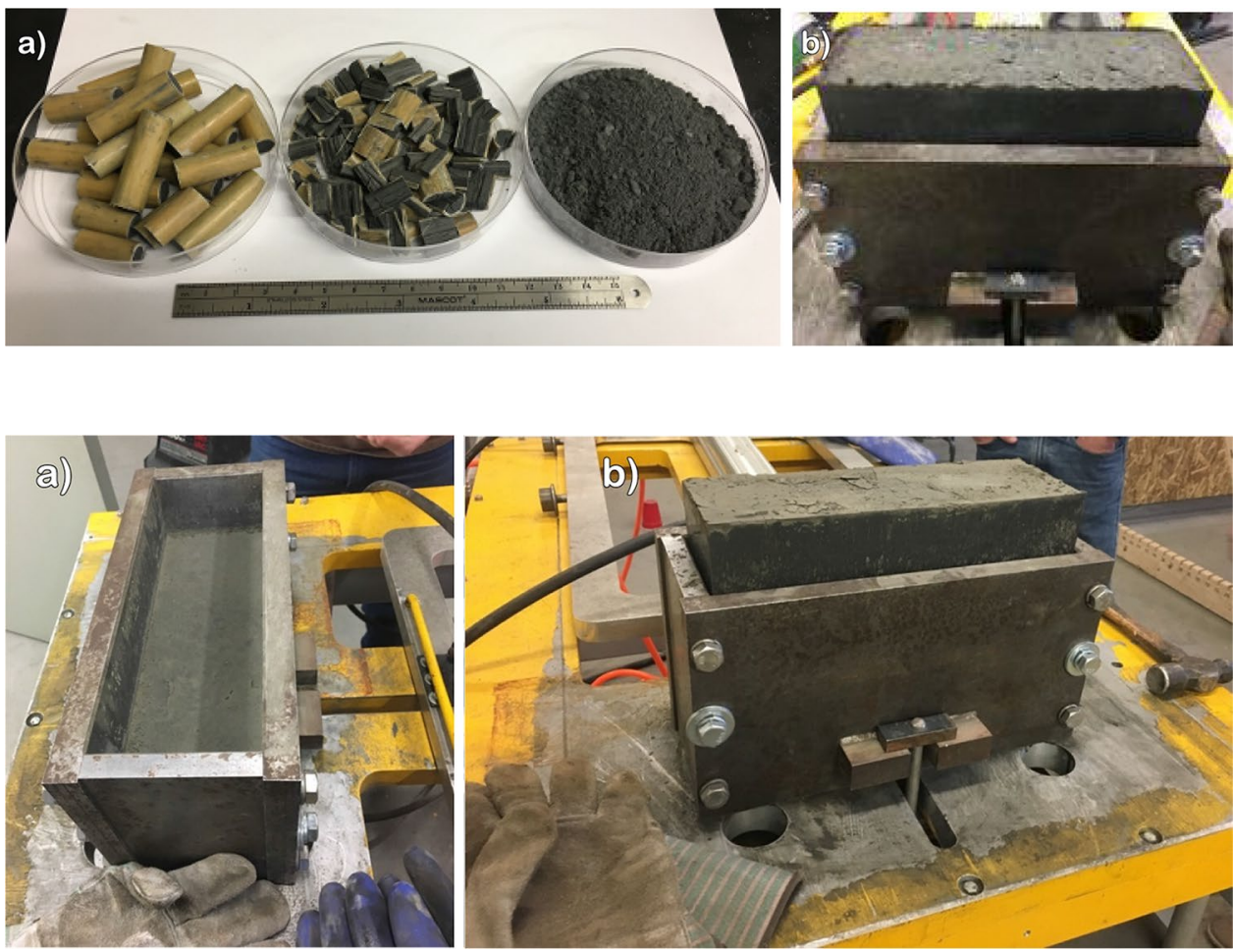

Fig. 5 a, b. Steel high-pressure compaction rectangular mold used in the dynamic compaction system after compaction a and after extraction $\mathbf{b}$
(2) neat Portland cement, (3) 6.0 wt\% HVCC "chips" + Portland cement, (4) 6.0 wt\% HVCC particle fiber powder $($ PFP) + Portland cement. One low pressure (LP) neat Portland cement sample was also included, for comparison. The low-pressure Portland cement specimens underwent standard hand compaction (tamping) with a rubber tool, using between 25 and $30 \mathrm{~N}$ of force to set the cement paste.

After compaction, the high-pressure compacted rectangular $31.5 \times 10 \times 6.8 \mathrm{~cm}$ blocks were pre-cured for
$24 \mathrm{~h}$ before being removed from the steel compaction mold. The four rectangular blocks were then submerged in tap water for 180 days at room temperature $\left(\sim 23^{\circ} \mathrm{C}\right)$, before being sliced into $5.0 \mathrm{~cm}^{3}$ cubes (Fig. 6b), after which saltwater aging experiments were performed on individually prepared cubes. A total of 24 Portland cement cube specimens were thus created for a total of three samples per specimen type. 
Fig. 6 a, b. High-pressure compacted rectangular blocks compressed at $2000 \mathrm{kN}(1-4)$, along with regular low-pressure cement compressed at 25-30 N (LP, middle), before curing (a) and a sliced cube with 6.0 wt\% of virgin carbon/ glass fibers before compression testing (b)
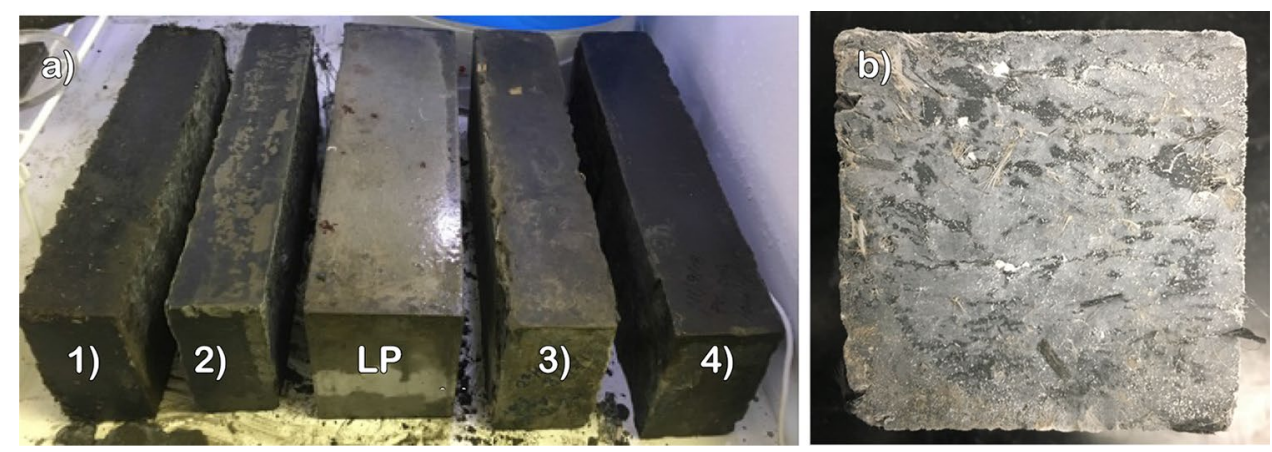

\subsubsection{Saltwater aging}

Saltwater aging on 12 of the 24 cubic samples was conducted to observe the saltwater resistance of the selected cement admixtures. Concrete structures typically experience long-term exposure in seawater, as they are exposed to salt and the ocean moisture, which contain chlorine and other corrosive compounds $[14,19,26,36]$. In real-world scenarios, mechanical wear and impact damage may occur by oceanwater wave impaction, or by the sand and gravel they carry, however below the surface, the seawater will ingress into the cement pores and surface voids $[7,8]$. Thus, salt aging corrosion is more likely to degrade low-pressure cured cement with more voids than highpressure compacted cement containing fewer voids [7, $8,11-15,37]$. We used ImageJ to analyze the dry sample surface areas of the voids in the microscopy images, which were estimated to be spherical in shape. The chord length (diameter) was measured to fall between 50 and $700 \mu \mathrm{m}$, with noticeable exceptions, as some of the voids where $>1.0 \mathrm{~mm}$. However, the voids in the high-pressure compacted cement decreased to 7-50 $\mu \mathrm{m}$ in size.

For the saltwater aging set, samples were situated in a $3.0 \%$ artificial aqueous solution that simulated ocean water at elevated temperatures of $83{ }^{\circ} \mathrm{C}$ for 30 days, to simulate accelerated aging in oceanic conditions. The aqueous seawater solution contained roughly $25 \mathrm{~g} / \mathrm{L}$ of sodium, magnesium, and calcium chlorides. Other known constituents of $<1 \mathrm{~g} / \mathrm{L}$ were also included in the artificial salt solution based on the ASTM D1141 standard [38], as noted in Table 3.

\subsubsection{Compression strength testing}

After manufacturing and curing of the cubic specimens for 180 days the high-pressure unaged and salt-water aged cement cubes containing either recyclate, virgin fibers, or no recyclate filler materials were strength tested using a high-strength compression frame system. A total of 12 cubic unaged samples were tested for compression strength, and 12 cubic specimens were exposed to
Table 3 Manufacturer specifications for simulated sea salt

\begin{tabular}{lll}
\hline Sodium Chloride & $\mathrm{NaCl}$ & $24.53 \mathrm{~g} / \mathrm{L}$ \\
\hline Magnesium Chloride & $\mathrm{MgCl} 2$ & $5.20 \mathrm{~g} / \mathrm{L}$ \\
Sodium Sulfate & $\mathrm{Na} 2 \mathrm{SO} 4$ & $4.09 \mathrm{~g} / \mathrm{L}$ \\
Calcium Chloride & $\mathrm{CaCl} 2$ & $1.16 \mathrm{~g} / \mathrm{L}$ \\
Potassium Chloride & $\mathrm{KCL}$ & $0.695 \mathrm{~g} / \mathrm{L}$ \\
Sodium Bicarbonate & $\mathrm{NaHCO} 3$ & $0.201 \mathrm{~g} / \mathrm{L}$ \\
Potassium Bromide & $\mathrm{KBr}$ & $0.101 \mathrm{~g} / \mathrm{L}$ \\
Boric Acid & $\mathrm{H} 3 B O 3$ & $0.027 \mathrm{~g} / \mathrm{L}$ \\
Strontium Chloride & $\mathrm{SrCl} 2$ & $0.0025 \mathrm{~g} / \mathrm{L}$ \\
Sodium Fluoride & $\mathrm{NaF}$ & $0.003 \mathrm{~g} / \mathrm{L}$ \\
Water & $\mathrm{H} 2 \mathrm{O}$ & $988.968 \mathrm{~g} / \mathrm{L}$ \\
& & Total: $1025 \mathrm{~g} / \mathrm{L}$ \\
\hline
\end{tabular}

saltwater conditions and then tested for compression as aged specimens. Compression testing was conducted on select cubes in accordance with the ASTM C109/C109M standard [30].

\section{Experimental results and discussion}

The maximum compression strengths of the unaged samples are shown in Fig. 7. All the high-pressure samples cured in water for 180 days had maximum compression strengths between 30 and $60 \mathrm{MPa}$ (Fig. 7). These relatively high compression strength results were likely due to the decreased porosity and lower permeability of the highpressure Portland cement, compared to low-pressure selfcompacted cement. In cement, most surface/internal voids and pores are the result of insufficient compaction, mixing, and placement of the created cement paste during curing, and as a result low-pressure compacted cements will have comparably more voids in their structures (Fig. 8a) $[14,25$, $27,39]$. Surface magnification of the high-pressure compact cement indicated fewer, and smaller voids after compaction compared to low-pressure compacted cement, however the high-pressure compacted cement sample did 
Fig. 7 Compression strengths of the high-pressure compacted unaged cement samples with and without recycled admixtures cured for 180 days

Fig. 8 a, b. a Post compression test analysis of the fractured prism specimens: low-pressure compacted cement with noticeably more internal voids compared to the high-pressure compacted cement $\mathbf{b}$, which also contained fracture cracks as a result of compression testing
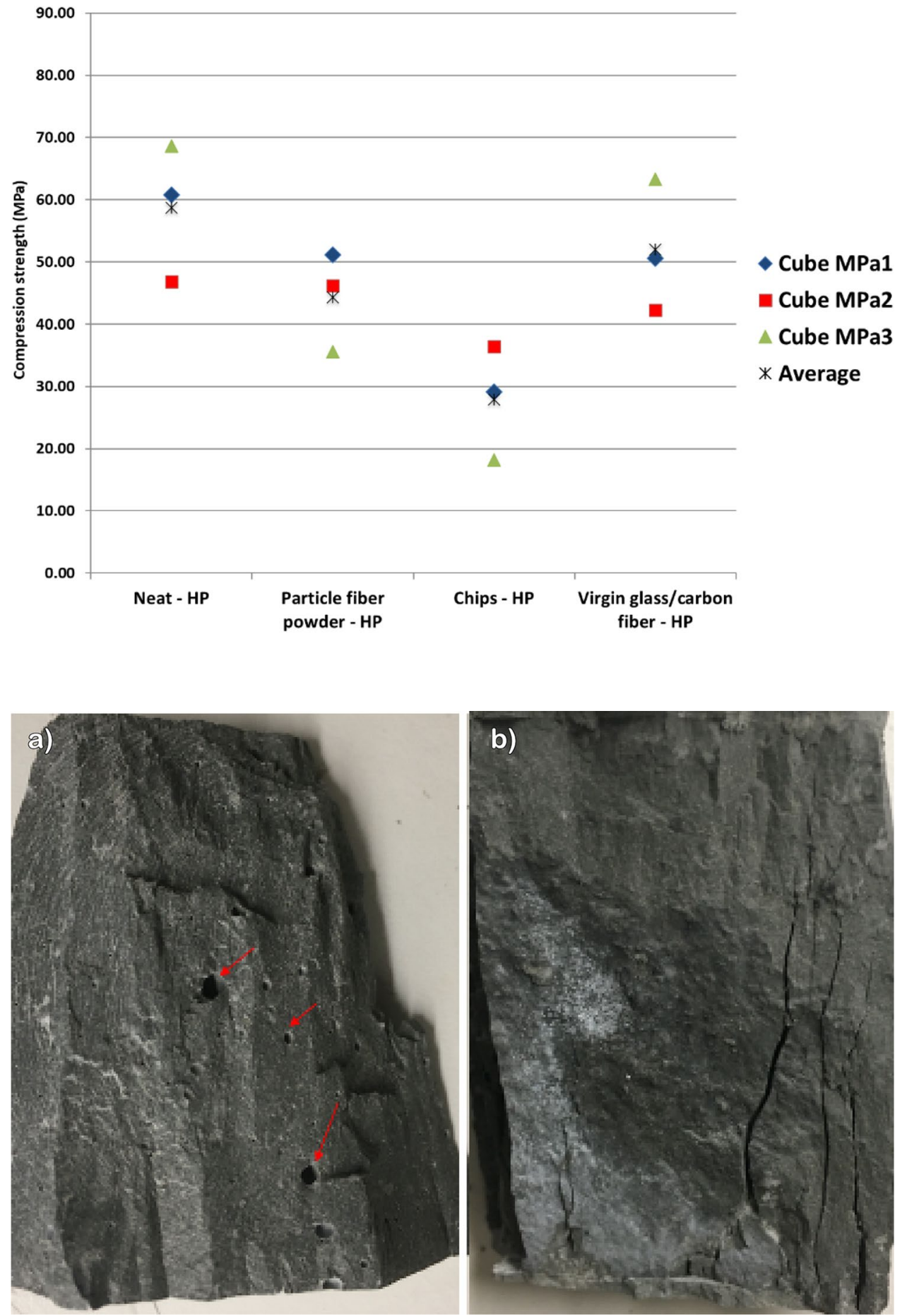

contain post-compression fracture stress cracks (Figs. 8a, $b$ and $9 a, b)$.

Surface microscopy analysis of the neat low-pressure compacted cement, neat high-pressure compacted cement, and high-pressure compacted cement samples containing the recyclate showed notable differences in surface characteristics. Numerous microscopic voids and cavities were visible in the neat low-pressure Portland cement samples (Fig. 10a) but absent in the high-pressure compacted sample (Fig. 10b). In the high-pressure compacted sample containing $6.0 \mathrm{wt} \%$ of HVCC particle fiber powder (PFP), individual fibers were visible as well as darker areas where the powder material was incorporated into the high-pressure compacted cement (yellow arrows), and overall fewer voids and cavities were observed compared to the low-pressure compacted cement. 
Fig. 9 a, b. $70 \times$ surface magnification of low-pressure compacted ordinary Portland cement a), and high-pressure Portland cement with 6.0 wt $\%$ of particle high-voltage conductor material b)
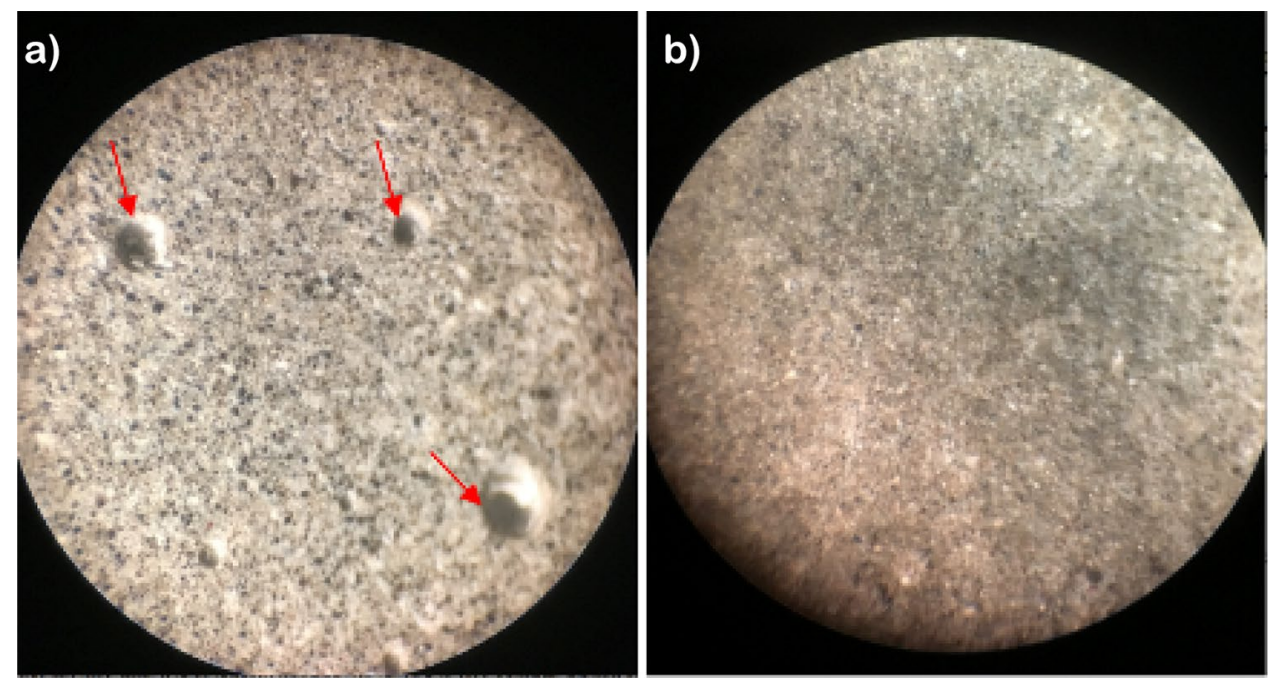

Fig. 10 a-c. $200 \times$ magnification of low pressure compacted Portland cement (a), high-pressure compacted Portland cement (b), and highpressure compacted cement with 6.0 wt $\%$ of PFP (c)
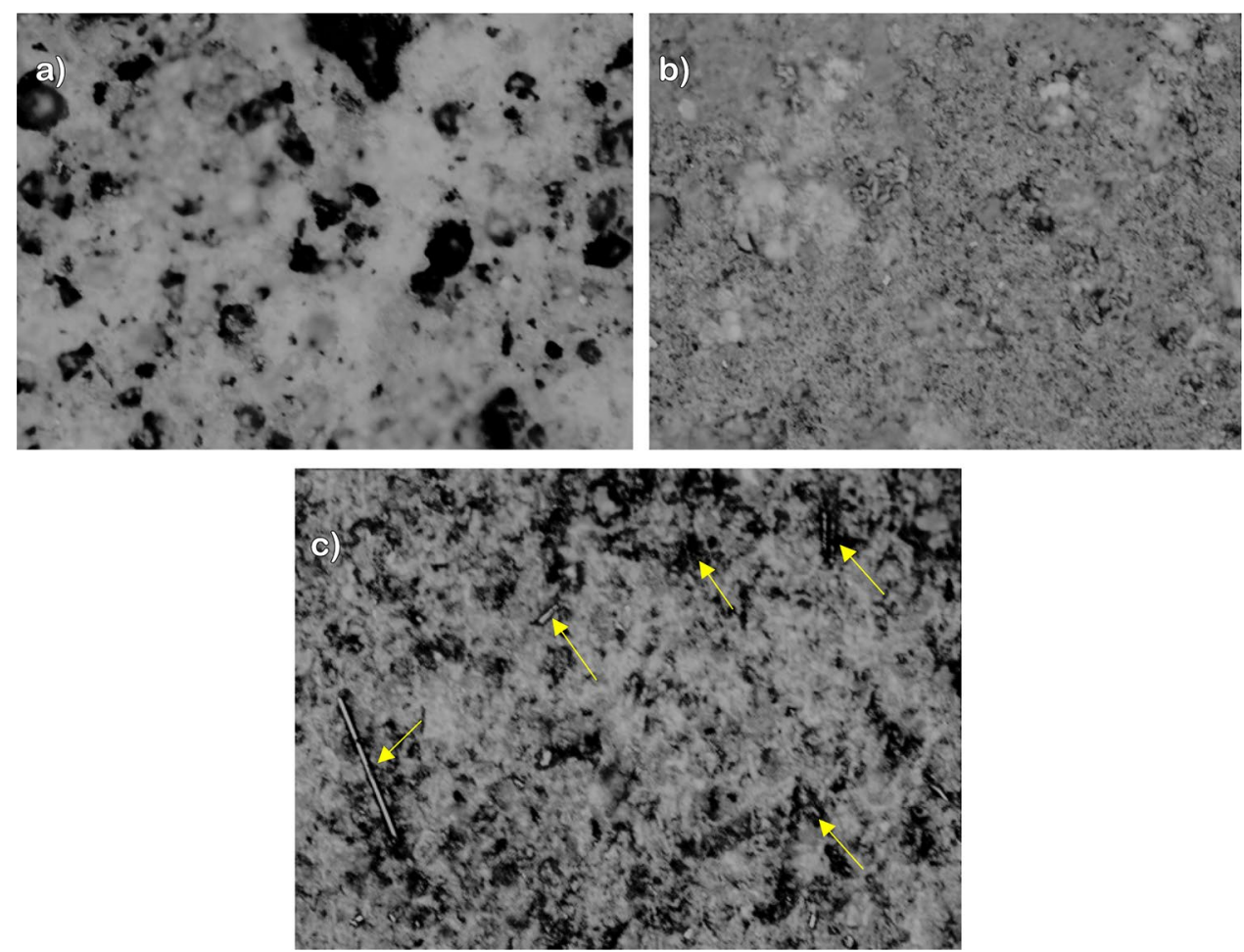

The salt-aged samples also showed marked differences in visual appearance, and visual observations of the highpressure compacted samples indicated visible surface efflorescence from salt-aging, as shown in Fig. 11a-e. This surface effect was similar to the surface efflorescence observed on the low-pressure compacted cement in our previous study. Large cracks and efflorescence were also noticeable in the high-pressure compacted $6.0 \mathrm{wt} \% \mathrm{HV}$ chips sample (Fig. 11c).

The compression test results of the salt aged samples showed that high-pressure compressed materials containing the recyclate admixtures had average compression strengths that were comparable to standard hydraulic concrete (Figs. 8, 12). The compression strength of the neat high-pressure compacted cement, which was water cured for 180 days, was roughly $10 \%$ of its average compression strength value after saltwater aging for 30 days. However, the cement specimens with the particle fiber powder admixture lost only $~ 7 \%$ average maximum compression strength after saltwater aging, for a final value of $41 \mathrm{MPa}$ (Fig. 12). This result was comparable to the averaged maximum compression strength of the unaged, nonsaltwater treated material, which was $44 \mathrm{MPa}$. However, compression strength values of the neat high-pressure

\section{SN Applied Sciences}




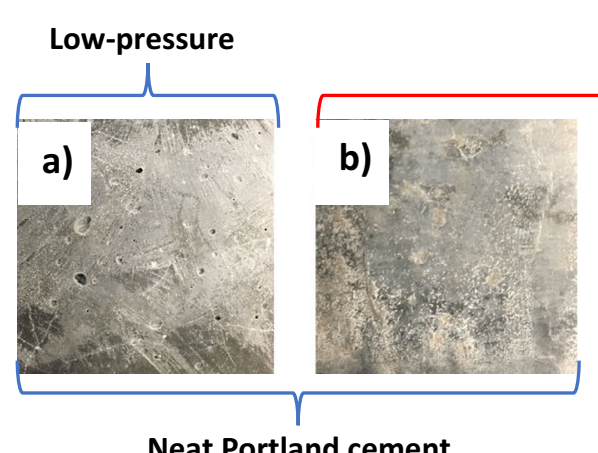

High-pressure

L

Neat Portland cement
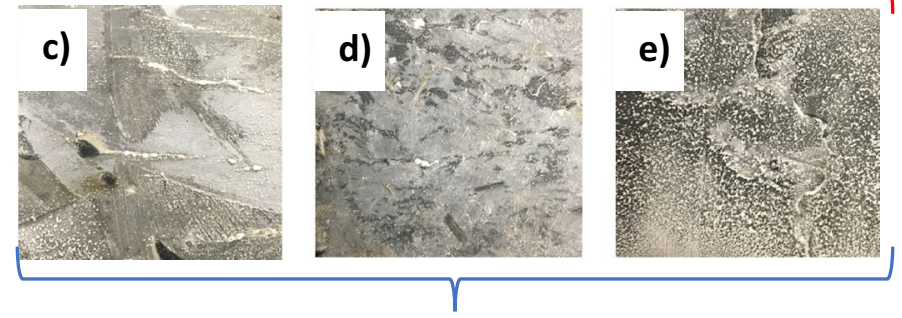

Portland cement with 6.0 wt \% FCP admixtures

Fig. 11 a-e. Cement mixtures of low-pressure and high-pressure compacted fiber mixtures

Fig. 12 Compression strengths of the high-pressure compacted cement with and without PFP admixtures after salt-aging for 30 days

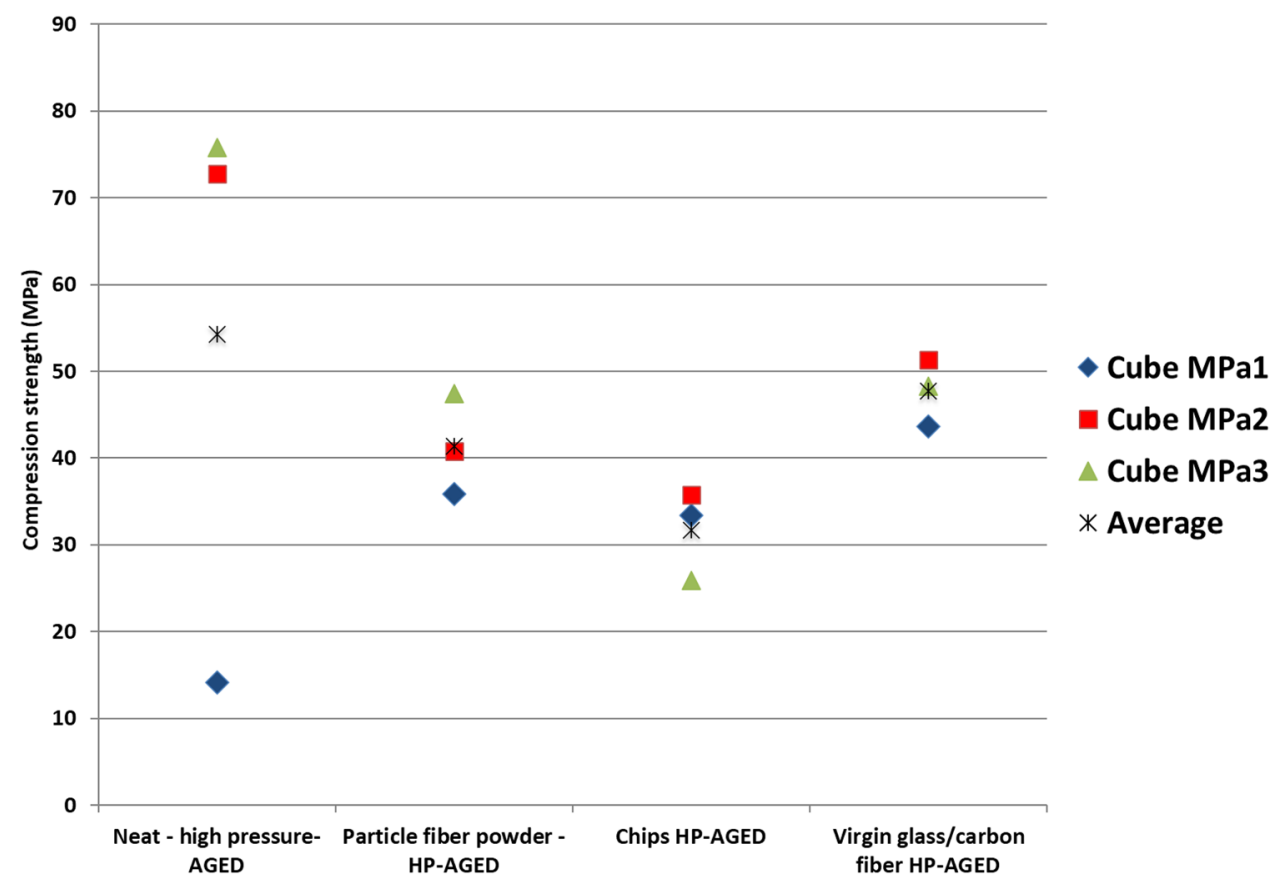

compacted exhibited greater variations in strength, likely due to embrittlement after saltwater aging. The neat highpressure compacted had the lowest single performing test value, but the highest overall compression strength. The combined virgin carbon and glass fiber admixture also lost very little compression strength, from 51 to $48 \mathrm{MPa}$, and the small decrease in strength was likely due to the nonpozzolanic effects of the carbon fiber particles. Although the newly manufactured (virgin) carbon/glass fiber admixture exhibited slightly average maximum compression strength after aging, they were not a recycled waste composite material, thus a slightly higher average compression strength was expected. Furthermore, although the recycled composite core chip admixture samples showed a notable increase in compression strength after aging, they exhibited the lowest performance, with an average compression strength decrease of $27 \%$. Therefore, from these mechanical compression testing results, we concluded that the addition of recycled particle fiber powder admixture noticeably mitigated the deleterious effects of saltwater aging such as salt (magnesium and sodium) sulfate/chloride attacks, allowing it to maintain its compression strength and effectively making the material more resistant to saltwater corrosion. This effect will be further examined in Sect. 4 with the assistance of molecular dynamics.

\section{Molecular dynamics}

Moisture ingress is a serious concern in cement-based materials, especially in saltwater environments, as moisture can carry damaging particles such as magnesium, sodium, and chlorine compounds, into the interior of the 
cement. Thus, a material that can limit moisture diffusion may consequently delay aging. To better recognize and evaluate the experimental results, a molecular dynamics model was created based on our previous research to illustrate ion diffusion through high-pressure cement [5]. This analysis was conducted by using Mean Squared Displacement (MSD) to determine molecular interactions with Portland cement, and HVCC particle fiber powder materials, under simulated low and high-pressure compaction conditions $[5,40,41]$.

\subsection{Molecular dynamics methods}

Simulated nanoscale-sized cement particles and fiber polymer blocks were created using Materials Studio's molecular dynamics software, using the same methods used in our previous work, with the addition of small fiber fragments (carbon and glass). These glass and carbon fragments were constructed as pre-constructed compounds using the Nanostructure module in Materials Studio [5]. To simulate the resin used in the experimental study, manually constructed epoxy fragments were also included in the form of bisphenol A (BPA), as these compounds are prevalent in many epoxies.

A total of three nanoscale Portland cement models were created: low-pressure standard density Portland cement (PCLP) as a baseline comparison, high-pressure high-density Portland cement (PCHP), and high-pressure high-density Portland cement containing the FCP admixture (PCpfHP). Finite-sized nanoscale molecular compounds of $\mathrm{SiO}_{2}, \mathrm{Fe}_{2} \mathrm{O}_{3}, \mathrm{Al}_{2} \mathrm{O}_{3}$, and $\mathrm{CaO}$, which make up a large portion of Portland cement, were also included in each model. The structures were placed in an Amorphous Cell lattice box $(7.8 \times 7.8 \times 7.8 \mathrm{~nm})$, at a weight percentage consistent to ordinary Portland cement (Table 1). The third high-pressure model contained nanoscale carbon and glass fibers, and epoxy (BPA) compounds, to simulate the experimental samples created in this study containing recycled admixtures [5, 40-42]. Each individual lattice box contained either seven $\mathrm{Na}^{+}, \mathrm{Mg}^{2+}$, or $\mathrm{Cl}^{-}$ions, to simulate the ingress of sodium chloride and magnesium chloride, as these compounds are present in seawater and are known to cause deleterious effects to cement-based materials in marine environments. The movements of these compounds through the lattices were assessed using MSD.

After creating the initial models using Amorphous cell, the two-high pressure/compacted models were 'compacted' using molecular dynamics NPT-the persistent or 'constant' number $(\mathrm{N})$ of molecules, pressure $(\mathrm{P})$, and the temperature $(\mathrm{T})$ - for 20 picoseconds at 3.0 GPa of pressure to reduce the cell density to approximately $3.4 \mathrm{~g} /$ $\mathrm{cm} 3$.[5] The temperature, volume, and number of molecules were held constant during NVT Forcite dynamics, after which analysis of corrosive ion diffusion through the cement and FCP materials was conducted using MSD (Eq. 1) [5]. The three molecular dynamics models (PCLP, PCHP, and P(pfHP) are shown in Figs. 13a, b and 14b, and the overall molecular dynamics build process is shown in Fig. 15.

After initial molecular dynamics, the MSD analysis tool was used to assess how quickly the ions moved throughout each system. This tool determined the number of molecules (Eq. 1) in each system, represented by $N$ for the diffusivity coefficient $(D)$ in a group of fixed atoms in calculating MSD [33, 40, 42].

$D=\frac{1}{6 N_{a}} \lim _{t \rightarrow \infty} \frac{d}{d t} \sum_{i=1}^{N_{a}}\left[r_{i}(t)-r_{i}(0)\right]^{2}$

Using Materials Studio, we utilized the MSD method to evaluate the molecular interactions of the $\mathrm{Cl}^{-} \mathrm{Na}^{+}$ions as they collided with one another and observed their
Fig. 13 a, b Molecular dynamics models of low pressure (PCLP), and high-pressure compacted Portland cement with particle fiber material (PCpfHP)

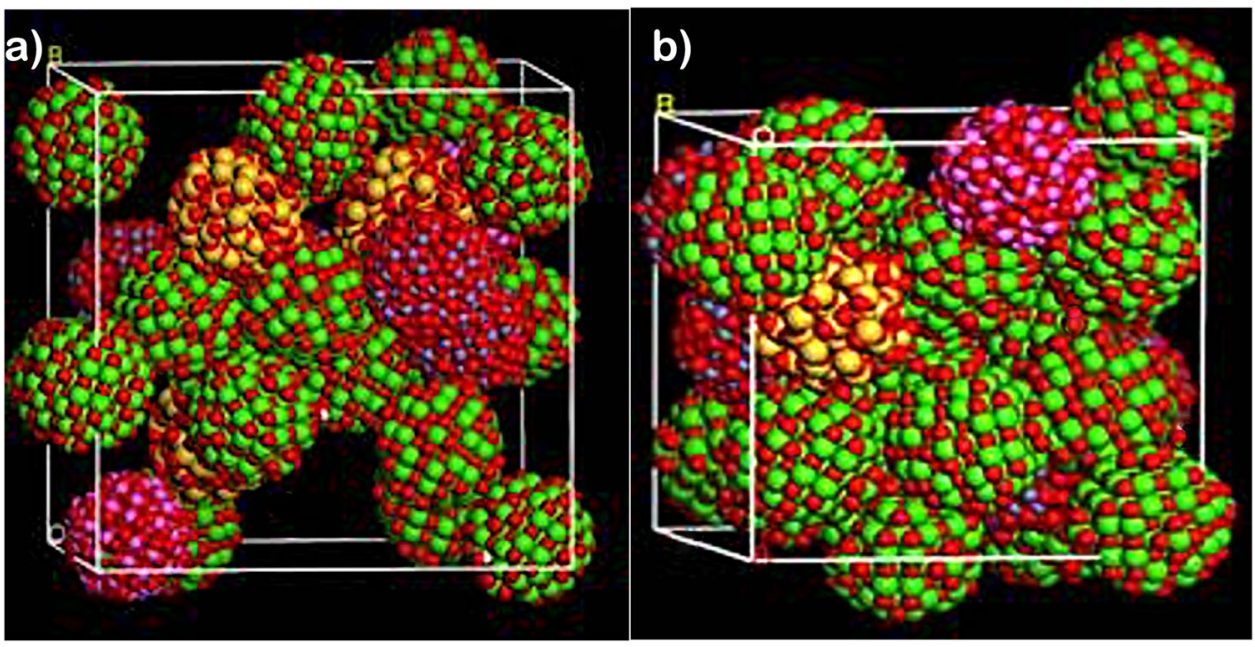




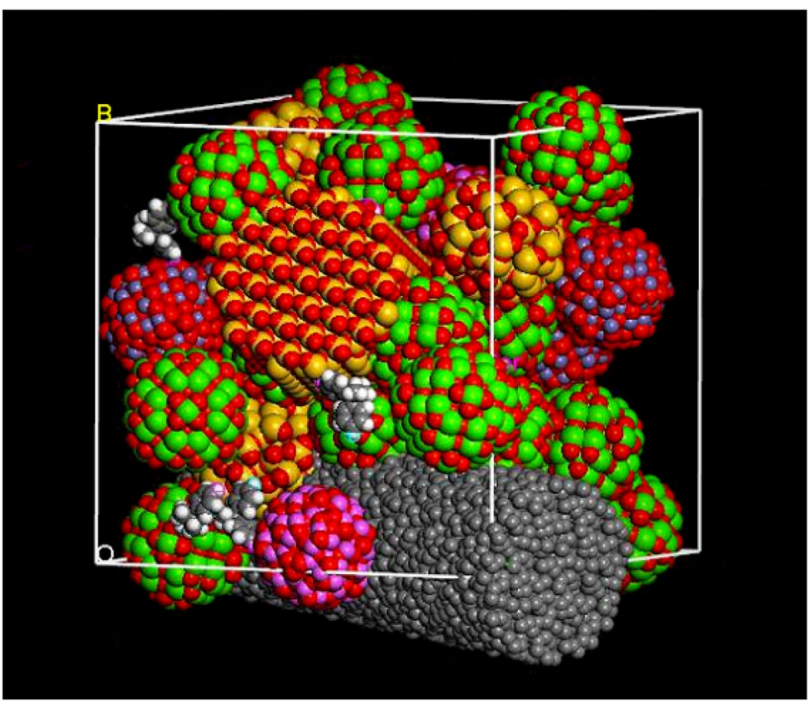

Fig. 14 Molecular dynamics model of high-pressure compacted Portland cement with particle fiber material (PCpfHP)

movements through the accessible or presented volume [33]. In MSD, even though there is a non-directional motion, a molecule will not maintain its proximity to its original location. Therefore, molecules will often meander or'wander' at a certain rate, as determined by their charge, the density of the material, and the relative temperature during the process of diffusion $[32,33]$. Thus, from this process, the rate of diffusion could be estimated by the speed of molecular movement.

\subsection{Molecular dynamics results and Discussion}

The diffusion rates of the $\mathrm{Cl}^{-}, \mathrm{Mg}^{2+}$, and $\mathrm{Na}^{+}$ions within the low and high-density cement models are illustrated in Figs. 16, 18, as a function of MSD over 10 ps. The results showed that the average $\mathrm{MSD} \mathrm{Cl}^{-}, \mathrm{Mg}^{2+}$, and $\mathrm{Na}^{+}$ion diffusion rates in the low-pressure Portland cement (containing no composite admixture components) were significantly higher after $10 \mathrm{ps,} \mathrm{compared} \mathrm{to} \mathrm{the} \mathrm{high-pressure} \mathrm{PCHP}$ and PCpfHP models. This indicated that $\mathrm{Cl}^{-}, \mathrm{Mg}^{2+}$, and $\mathrm{Na}^{+}$ ions would be more likely to diffuse, and would diffuse faster, through standard low-pressure cement material. By contrast, the high-pressure compacted models showed lower overall MSD rates for the $\mathrm{Cl}^{-}, \mathrm{Mg}^{2+}$, and $\mathrm{Na}^{+}$ions. Notably, high pressure compaction alone did not reduce diffusion nearly as much as the simulated compacted model containing admixture components. Thus, while the high-pressure simulations had lower rates of $\mathrm{Cl}^{-}, \mathrm{Mg}^{2+}$, and $\mathrm{Na}^{+}$ion diffusion, the high-pressure models containing carbon and glass fibers with epoxy components had the lowest diffusion rates, with final MSD values of $<50$ for the PCpfHP models. As a result, $\mathrm{Cl}^{-}$ion diffusion in the
PCpfHP model decreased by 88\% compared to the PCLP model, $\mathrm{Mg}^{2+}$ ion diffusion decreased by $\sim 85 \%$, and $\mathrm{Na}^{+}$ ion diffusion decreased by $\sim 80 \%$ in the PCpfHP model, compared to the PCLP model. Therefore, in all simulations, the $\mathrm{Cl}^{-}, \mathrm{Mg}^{2+}$, and $\mathrm{Na}^{+}$ions diffused through the higher density Portland cement materials containing admixtures at slower rates, with an average of $84 \%$ decrease (Fig. 16, $17,18)$.

Because damage to Portland cement structures can be exacerbated by moisture (water) ingress, especially in high chloride solutions such as marine environments, lower rates of $\mathrm{Na}^{+}, \mathrm{Mg}^{2+}$, and $\mathrm{Cl}^{-}(\mathrm{MgCl}$ and $\mathrm{NaCl})$ species diffusion are preferable. Notably, a comparison of $\mathrm{Mg}^{2+}$ and $\mathrm{Na}^{+}$diffusion rates showed that while $\mathrm{Mg}^{2+}$ diffused $\sim 12 \%$ faster than $\mathrm{Na}^{+}$in the PCLP model, the diffusion of $\mathrm{Mg}^{2+}$ was slower than $\mathrm{Na}^{+}$in the PCHP and PCpfHP models, by $\sim 11 \%$ and $\sim 14 \%$. Therefore, these results indicated that the combined effects of high pressure and the fiber and resin components helped to slow the diffusion of $\mathrm{Mg}^{2+}$ ions. This is significant, as $\mathrm{MgCl}$ is known to have deleterious effects on cement and concrete materials, even compared to $\mathrm{NaCl}$, in marine environments.

Thus, our molecular dynamics results indicated that the presence of fiber and resin components, combined with a denser overall material, endowed the material with fewer migratory pathways for the corroding ionic compounds, effectively delaying ionic migration. While Portland cement is a typically porous that typically assists in ion mobility, the molecular dynamics results verified that high pressure compaction could significantly delay salt aging, and supported the compression strength results obtained in this work, showing that the high-pressure compacted materials with admixtures retained $90 \%$ of their strength. Of note, while the molecular dynamics results showed that corrosive ion diffusion was delayed, standard water diffusion may also be affected, which is required for curing. Therefore, curing times for high-pressure compacted samples in real-world circumstances may need to be extended, as standard moisture ingress would require more time to travel to the interior of the material and initiate the heat of hydration reaction. As a result, this may be a limitation of this material in some applications, and this topic will be investigated in our future work.

\section{Conclusions}

Of the various FCP admixtures and Portland cement mixture combinations evaluated in this study, the $6.0 \mathrm{wt} \%$ high-pressure compacted ground particle fiber powder sample retained $90 \%$ of its average maximum compression strength after aging in saltwater for 30 days, compared to the neat ordinary Portland cement on average. 
Fig. 15 Build process for the molecular dynamics models, which examined $\mathrm{Na}^{+}, \mathrm{Mg}^{2+}, \mathrm{Cl}^{-}$ ion movement through high and low pressure compacted nanoscale Portland cement with and without FCP admixtures

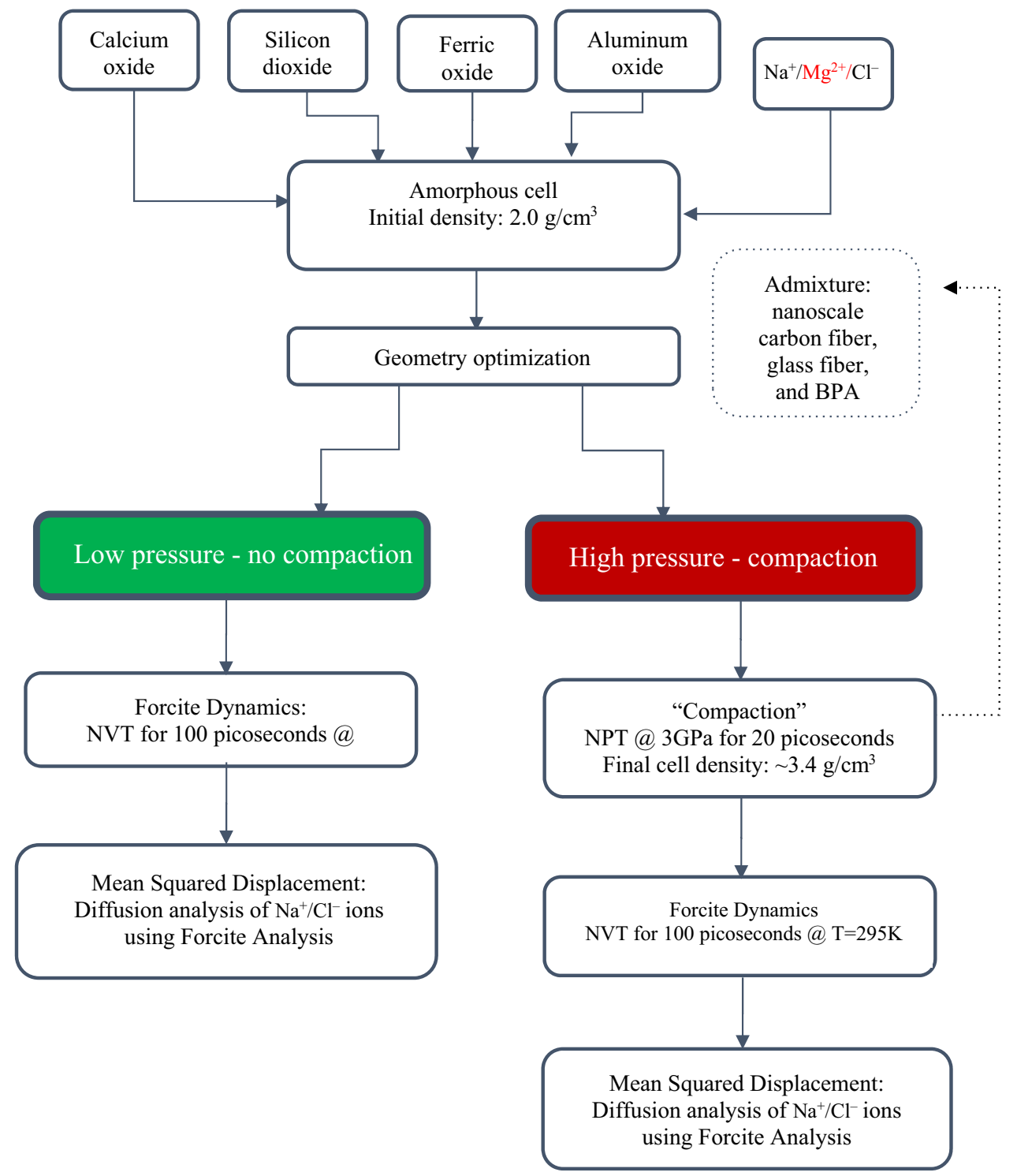

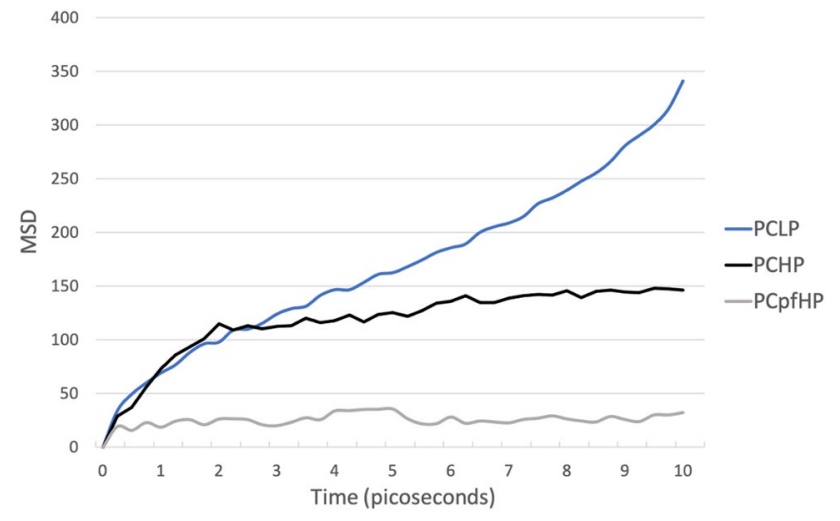

Fig. 16 Diffusion of $\mathrm{Cl}^{-}$ions through low-pressure Portland cement (PCLP) in blue, high-pressure Portland cement (PCHP) in grey, and Portland cement with particle hybrid glass and carbon fiber FCP material (PCpfHP) in black

\section{SN Applied Sciences}

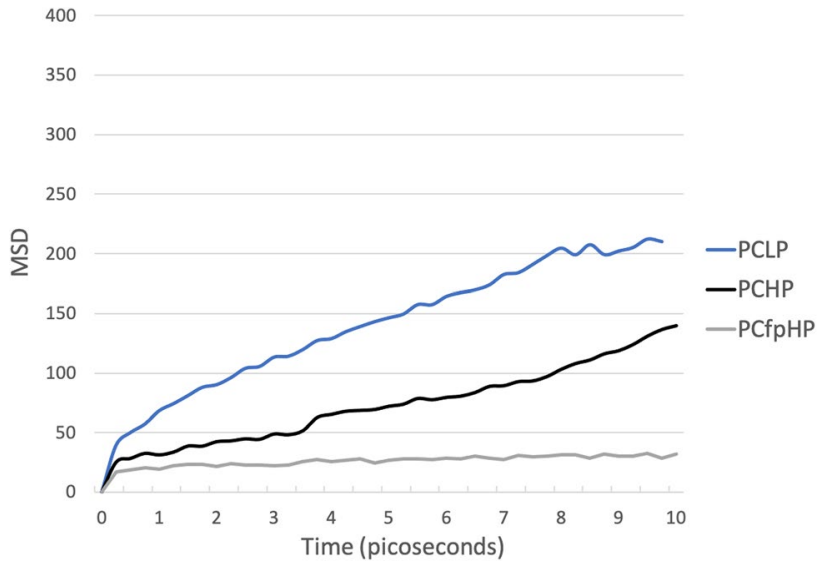

Fig. 17 Diffusion of $\mathrm{Na}^{+}$ions through low-pressure Portland cement (PCLP) in blue, high-pressure Portland cement (PCHP) in black, and Portland cement with particle hybrid glass and carbon fiber FCP material (PCpfHP) in grey 


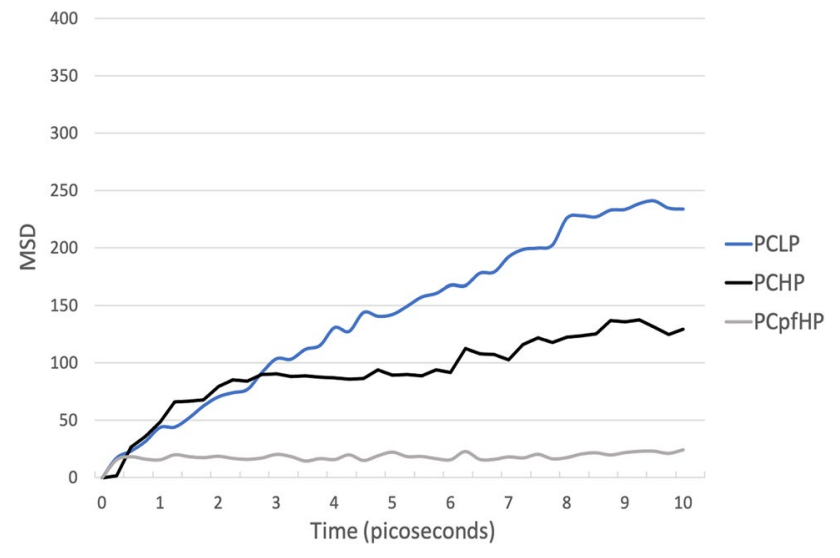

Fig. 18 Diffusion of $\mathrm{Mg}^{2+}$ ions through low-pressure Portland cement (PCLP) in blue, high-pressure Portland cement (PCHP) in black, and Portland cement with particle hybrid glass and carbon fiber FCP material (PCpfHP) in grey

Although the average compression strength of the neat Portland cement and virgin glass fiber admixture samples were higher, they experienced more deleterious effects on compression strength compared to the particle fiber powder sample. Therefore, specifically mixing the ground fiber composite waste material into cement could be used to retard water ingress and delay the diffusion of reactive ions in highly compacted hydraulic Portland cement.

The averaged maximum compression strength retention of the high-pressure compacted cement, specifically the heated saltwater aged particle fiber powder recyclate admixture, supported the possibility of recycling powder FCP waste materials into cement-based materials structures for highly saline, corrosive submersion environments. This study showed that finely ground, recycled FCP waste can be used in high-pressure compacted Portland cement to improve density and reduce porosity, creating a material that can substantially mitigate diffusion of deleterious compounds in saltwater $\left(\mathrm{Cl}^{-}, \mathrm{Mg}^{2+}\right.$, and $\mathrm{Na}^{+}$ions) by an average of $84 \%$. Therefore, the high-pressure compacted cementitious material with recycled polymer fiber waste may be advantageous for use in some structural applications that require extended service life in saltwater, as it retained most of its average compression strength even after accelerated salt aging.

While the experimental findings and numerical models in this study supported the possibility of recycling carbon and glass fiber polymer HVCC waste into concrete, this study still contained a few limitations. For example, while the high-pressure compacted material showed promise, further investigations will be needed to assess its use as a building material in real-life situations in offshore environments. Additionally, while the high-pressure vibratory compaction system was beneficial in reducing voids and increasing the density of the cement samples, its relatively high cost, limited mobility, and extended curing time could limit the applications of these cement structures. Nevertheless, we showed that with proper treatment and processing of waste FCP materials, recycling of this waste into cement-based materials may be a valuable alternative to disposal in landfills.

Acknowledgements Thank you to Frank Valdez at the United States Bureau of Reclamation for assistance with sample testing, thank you to CTC Global for funding this research, and a special thank you to Dr. Robert Amme for research assistance and support.

Funding This work was funded by the National Science Foundation I/UCRC Center for Novel High Voltage Materials and Structures under \#IIP 1362135 and by the NSF Grant Opportunities for Academic Liaison with Industry program under \#CMMI-123252, in collaboration with CTC Global.

\section{Declarations}

Conflict of interest Dr. Edward Clark received a research grant from CTC Global through the NSF Grant Opportunities for Academic Liaison with Industry program.

Data availability Data available on request from the authors.

Code availability Code available on request from the authors.

Open Access This article is licensed under a Creative Commons Attribution 4.0 International License, which permits use, sharing, adaptation, distribution and reproduction in any medium or format, as long as you give appropriate credit to the original author(s) and the source, provide a link to the Creative Commons licence, and indicate if changes were made. The images or other third party material in this article are included in the article's Creative Commons licence, unless indicated otherwise in a credit line to the material. If material is not included in the article's Creative Commons licence and your intended use is not permitted by statutory regulation or exceeds the permitted use, you will need to obtain permission directly from the copyright holder. To view a copy of this licence, visit http://creativecommons. org/licenses/by/4.0/.

\section{References}

1. Oliveux G, Dandy LO, Leeke GA (2015) Current status of recycling of fibre reinforced polymers: review of technologies, reuse and resulting properties. Prog Mater Sci 72:61-99

2. Witik RA, Teuscher R, Michaud V, Ludwig C, Månson JAE (2013) Carbon fibre reinforced composite waste: an environmental assessment of recycling, energy recovery and landfilling. Compos A Appl Sci Manuf 49:89-99

3. Bhadra J, Al-Thani N, Abdulkareem A (2017) Recycling of polymer-polymer composites. In: Micro and nano fibrillar composites (MFCs and NFCs) from polymer blends, pp 263-277. Woodhead Publishing

4. Dehghan A, Peterson K, Shvarzman A (2017) Recycled glass fiber reinforced polymer additions to Portland cement concrete. Constr Build Mater 146:238-250 
5. Clark E, Bleszynski M, Valdez F et al (2020) Recycling carbon and glass fiber polymer matrix composite waste into cementitious materials. Resour Conserv Recycl 155:104659

6. Yang X (2017) Study on slamming pressure calculation formula of plunging breaking wave on sloping sea dike. Int J Naval Archit Ocean Eng 9(4):439-445

7. Costa A, Appleton J (2002) Case studies of concrete deterioration in a marine environment in Portugal. Cement Concr Compos 24(1):169-179

8. Real S, Bogas JA (2018) Chloride ingress into structural lightweight aggregate concrete in real marine environment. Mar Struct 61:170-187

9. Yamini OA, Mousavi SH, Kavianpour MR (2019) Experimental investigation of using geo-textile filter layer in articulated concrete block mattress revetment on coastal embankment. J Ocean Eng Mar Energy 5(2):119-133

10. Luznik L, Flack KA, Lust EE, Taylor K (2013) The effect of surface waves on the performance characteristics of a model tidal turbine. Renew Energy 58:108-114

11. Zhang Y, Zang W, Zheng J, Cappietti L, Zhang J, Zheng Y, Fernandez-Rodriguez E (2021) The influence of waves propagating with the current on the wake of a tidal stream turbine. Appl Energy 290:116729

12. Narayan S, Beck MW, Reguero BG, Losada IJ, Van Wesenbeeck B, Pontee N, Burks-Copes KA (2016) The effectiveness, costs and coastal protection benefits of natural and nature-based defences. PLoS ONE 11(5):e0154735

13. Wu K, Long J, Xu L, De Schutter G (2019) A study on the chloride diffusion behavior of blended cement concrete in relation to aggregate and ITZ. Constr Build Mater 223:1063-1073

14. Wang G, Wu Q, Zhou H, Peng C, Chen W (2021) Diffusion of chloride ion in coral aggregate seawater concrete under marine environment. Constr Build Mater 284:122821

15. Becker J, Ley $T$ (2019) Concrete pumping effects on air-entrained voids in concrete mixtures (No. SPTC14. 1-38-F). Southern Plains Transportation Center

16. Mansor AM, Borg RP, Hamed AM, Gadeem MM, Saeed MM (2018). The effects of water-cement ratio and chemical admixtures on the workability of concrete. In: IOP conference series: materials science and engineering, 442, p. 012017. IOP Publishing

17. Živica V, Križma M (2011) Dependence of efficiency of pressure compaction on the cement type used. Constr Build Mater 25(7):3073-3077

18. Van Damme H (2018) Concrete material science: Past, present, and future innovations. Cem Concr Res 112:5-24

19. Wu K, Kang W, Xu L, Sun D, Wang F, De Schutter G (2018) Damage evolution of blended cement concrete under sodium sulfate attack in relation to ITZ volume content. Constr Build Mater 190:452-465

20. Stynoski P, Mondal P, Marsh C (2015) Effects of silica additives on fracture properties of carbon nanotube and carbon fiber reinforced Portland cement mortar. Cement Concr Compos 55:232-240

21. Nassiri S, AlShareedah O, Rodin H, Englund K (2021) Mechanical and durability characteristics of pervious concrete reinforced with mechanically recycled carbon fiber composite materials. Mater Struct 54(3):1-18

22. Mastali M, Dalvand A, Sattarifard A (2017) The impact resistance and mechanical properties of the reinforced self-compacting concrete incorporating recycled CFRP fiber with different lengths and dosages. Compos B Eng 112:74-92

23. Mohajerani A, Vajna J, Cheung THH, Kurmus $\mathrm{H}$, Arulrajah A, Horpibulsuk S (2017) Practical recycling applications of crushed waste glass in construction materials: a review. Constr Build Mater 156:443-467

24. Chuang W, Geng-sheng J, Bing-liang L, Lei P, Ying F, Ni G, Kezhi $L$ (2017) Dispersion of carbon fibers and conductivity of

SN Applied Sciences carbon fiber-reinforced cement-based composites. Ceram Int 43(17):15122-15132

25. Ouyang X, Wang L, Fu J, Xu S, Ma Y (2021) Surface properties of clay brick powder and its influence on hydration and strength development of cement paste. Constr Build Mater 300:123958

26. Li L, Wang R, Zhang S (2019) Effect of curing temperature and relative humidity on the hydrates and porosity of calcium sulfoaluminate cement. Constr Build Mater 213:627-636

27. Vázquez-Rodríguez FJ, Elizondo-Villareal N, Verástegui LH, Arato Tovar AM, López-Perales JF, Contreras de León JE, Rodríguez Castellanos EA (2020) Effect of mineral aggregates and chemical admixtures as internal curing agents on the mechanical properties and durability of high-performance concrete. Materials 13(9):2090

28. Azmee NM, Shafiq N (2018) Ultra-high performance concrete: From fundamental to applications. Case Stud Constr Mater 9:e00197

29. Chang W, Hao M, Zheng W (2021) Strength and ductility of laterally confined concrete. Struct Concr. https://doi.org/10.1002/suco. 202000299

30. American Society for Testing and Materials (ASTM) (2020) Standard Test Method for Compressive Strength of Hydraulic Cement Mortars (Using 2-in. or [50 mm] Cube Specimens), ASTM C 109. United States of America: American Society for Testing and Materials

31. Amme RC, Pressey R, Weir K, Frey D (2000) Resonant shock compaction: ash-based construction blocks. In: Sustainable construction: use of incinerator ash, pp 355-367. Thomas Telford Publishing

32. Azéma E, Radjai F, Peyroux R, Dubois F, Saussine G (2006) Vibrational dynamics of confined granular materials. Phys Rev $E$ 74(3):031302

33. Amme RC (2004) Vibratory shock compaction of granular nuclear waste. In: APS April Meeting Abstracts, 2004, pp B15-005)

34. Feng SJ, Tan K, Shui WH, Zhang Y (2013) Densification of desert sands by high energy dynamic compaction. Eng Geol 157:48-54

35. Roy DM, Gouda GR, Bobrowsky A (1972) Very high strength cement pastes prepared by hot pressing and other high pressure techniques. Cem Concr Res 2(3):349-366

36. Dutzer V, Dridi W, Poyet S, Le Bescop P, Bourbon X (2019) The link between gas diffusion and carbonation in hardened cement pastes. Cem Concr Res 123:105795

37. Birchall JD, Howard AJ, Kendall K (1981) Flexural strength and porosity of cements. Nature 289(5796):388-390

38. American Society for Testing and Materials (ASTM) (2021) Standard Practice for the Preparation of Substitute Ocean Water. ASTM D1 141 - 98. United States of America. American Society for Testing and Materials

39. Chen X, Wu S, Zhou J (2013) Influence of porosity on compressive and tensile strength of cement mortar. Constr Build Mater 40:869-874

40. Kalinichev AG, Wang J, Kirkpatrick RJ (2007) Molecular dynamics modeling of the structure, dynamics and energetics of mineralwater interfaces: application to cement materials. Cem Concr Res 37(3):337-347

41. Cho BH, Chung W, Nam BH (2020) Molecular dynamics simulation of calcium-silicate-hydrate for nano-engineered cement composites-a review. Nanomaterials 10(11):2158

42. Bleszynski M et al (2016) Silicone rubber RTV-1 aging in the presence of aqueous salt. IEEE Trans Dielectr Electr Insul 23(5):2822-2829

Publisher's Note Springer Nature remains neutral with regard to jurisdictional claims in published maps and institutional affiliations. 